\title{
Schizophrenia: increased risk associated with winter and city birth - a case-control study in 12 regions within England and Wales
}

\author{
Noriyoshi Takei, Pak C Sham, Eadbhard O'Callaghan, Gyles Glover, \\ Robin M Murray
}

In a recent Swedish study, Lewis et al found that the risk of schizophrenia was greater in people brought up in cities than in those brought up in rural areas. The factors responsible for this effect are uncertain but a winter birth excess has been consistently reported in schizophrenia. ${ }^{2}$ We suggest that the same factors are responsible for both the urban/ rural difference in risk and the winter birth excess. We predict (a) winter birth and urban birth are each associated with an increased risk of schizophrenia; and (b) the effects of winter birth and urban birth potentiate each other.

\section{Genetic Section, \\ Department of \\ Psychological \\ Medicine, Institute of \\ Psychiatry, London \\ SE5 8AF \\ N Takei \\ P C Sham \\ R M Murray}

Cluain Mhuire Family

Centre, Blackrock, Co Dublin, Ireland

E O'Callaghan

Department of Public

Health and

Epidemiology,

Charing Cross and

Westminster Medical

School, London

G Glover

Correspondence to: Professor R M Murray.

Accepted for publication July 1994

$(\Im$ Epidemiol Community Health 1995;49:106-7) health authorities (RHAs) information on the sex, age, date of birth, and place of birth of first admission psychiatric patients born between 1938 and 1963 in England or Wales, and discharged between 1976 and 1986, who received a diagnosis of schizophrenia (ICD 295). Similar data on patients with a diagnosis of affective psychosis (ICD 296), personality (ICD 300), or neurotic disorder (ICD 297) were obtained and used as controls for the schizophrenic

To classify the patients according to place of birth, we used data from OPCS to identify 65 districts in England and Wales as "cities". These districts were conurbation areas with high population density throughout the period 1938-63. The rest of England and Wales was
Methods: We obtained from 12 regional patients.

Parameter estimates of the best logistic regression model allowing for confounding factors

\begin{tabular}{lllllll}
\hline \multirow{3}{*}{ Place of birth } & Season of birth & No of cases & No of controls & Estimate & $(95 \%$ CI $)$ \\
\hline \multirow{4}{*}{ City } & & & & & \\
& Autumn & 606 & 1499 & $1 \cdot 193$ & $(1.057,1 \cdot 347)$ \\
& Winter & 679 & 1636 & $1 \cdot 213$ & $(1.079,1 \cdot 364)$ \\
& Spring & 700 & 1872 & 1.082 & $(0.964,1 \cdot 213)$ \\
& Summer & 582 & 1678 & 1.009 & $(0.894,1 \cdot 139)$ \\
& Autumn & 901 & 2691 & 0.978 & $(0.880,1 \cdot 088)$ \\
& Winter & 952 & 2814 & 0.985 & $(0.886,1 \cdot 096)$ \\
& Spring & 1127 & 3222 & $1 \cdot 029$ & $(0.878,1 \cdot 075)$ \\
& Summert & 986 & 2893 & 1 & - \\
\hline
\end{tabular}

* In the logistic regression, sex, birth period, and age of onset were controlled for as potential confounders.

† Reference category: non-city summer birth

Cases $=$ schizophrenics $(n=6533)$ :

controls = comprised by three diagnostic groups; (affective disorders $n=4398$, personality disorders $n=4298$, neurotic disorders $n=9609$ )

These parameter estimates were obtained by reparametarising the final model for ease of interpretation. considered as "non-cities". Season of birth was defined as a categorical variable: winter (December-February), spring (March-May), summer (June-August), and autumn (September-November). To allow for potential confounding, we identified the sex, birth period (five, 5 year periods), and age of admission (under or over 26 years) of each subject.

To compare the schizophrenic and the control groups in respect of the exposure variables, we used linear logistic regression. Diagnostic status (schizophrenia $v$ control) was defined as the response variable. Models were fitted with different combinations of predictor variables. The statistical significance of a predictor variable was assessed by the reduction in deviance $\left(G^{2}\right)$ with its inclusion into the model.

Results: The inclusion of possible confounders into the logistic regression model resulted in significant reductions in $\mathrm{G}^{2}$ for sex and birth period, but not for age of onset. However, all three variables were retained so as to allow for them. When place of birth was entered into the model, $G^{2}$ was reduced by $14 \cdot 25(\mathrm{df}=1)$, implicating a significant $(p=0.0002)$ influence of place of birth on the diagnosis of schizophrenia in adult life. The inclusion of season of birth into the model, with or without the inclusion of place of birth, resulted in no significant improvement in goodness of fit. However, adding the interaction of season of birth and place of birth into the model, reduced $G^{2}$ by $8.43(\mathrm{df}=3)$, indicating that the effect of place of birth was significantly influenced $\mathrm{p}[=$ 0.038 ) by the season of birth.

The final model therefore includes the five main effects (sex, birth period, age of onset, place of birth and season of birth) and the interaction between place of birth and season of birth. The odds ratio (OR) in the final model for the association between "city birth" and schizophrenia, allowing for potential confounders, was $1 \cdot 12(95 \%$ CI $1 \cdot 057,1 \cdot 189)$. The ORs obtained from the final model are given in the table, which shows that city birth was associated with an increased risk of schizophrenia in those born in autumn (OR 1.19) and winter (OR 1.21), while those born in summer showed no city birth effect (OR 1.01). 
Discussion: Individuals born in cities and winter are at increased risk of schizophrenia. Moreover, the city birth effect seems to be modified by the season of birth. City birth did not increase the risk of schizophrenia among those born in summer, but was associated with a $21 \%$ increase among the winter born. The confirmation of our predictions suggests that adverse events at or before birth are at least partly responsible for the association between urban upbringing and increased risk of schizo- phrenia found in the recent Swedish cohort study. ${ }^{1}$

We thank the Regional Health Authorities for providing Mental Health Enquiry data, and the Office of Population Censuses and Surveys for providing population data. We are grateful to the Psychiatry Research Trust and the Wellcome Trust (P,S,). This was also supported in part by a Wellcome Training Fellowship in Clinical Epidemiology (NT)

1 Lewis D, David A, Andréasson S, Allebeck P. Schizophrenia and city life. Lancet 1992;340:137-40.

2 Hare E. Temporal factors and trends, including birth seasonality and the viral hypothesis. In: Nasrallah HA, ed. Handbook of schizophrenia, Vol 3. Amsterdam: Elsevier, 1988

\section{Insulin dependent diabetes mellitus: incidence in childhood in Belgrade 1982-92}

\section{Institute of \\ Epidemiology, School of Medicine, Belgrade University, \\ Višegradska 26, 11000 \\ Belgrade, Yugoslavia HD Vlajinac \\ BM Bojović \\ SB Šipetić \\ BJ Adanja \\ MS Jarebinski}

University Children's Hospital, Belgrade

SZ Radmanović

Mother and Child Institute, Belgrade DS Zdravković

\section{Correspondence to:}

Dr H Vlajinac.

Accepted for publication June 1994

$(\mp$ Epidemiol Community Health 1995;49:107-8)
Hristina D Vlajinac, Božidar M Bojović, Sandra B Šipetić, Benko J Adanja, Mirjana S Jarebinski, Slobodan Z Radmanović, Dragan S Zdravković

A retrospective technique was used to register all newly diagnosed cases of insulin dependent diabetes mellitus (IDDM) in Belgrade children 0-14 years of age, between 1982 and 1992 . Two independent sources of data were used: patients' records from hospitals where the disease was diagnosed (according to WHO criteria $^{1}$ ) and the population based register. To establish the completeness of ascertainment the capture/recapture method was used. ${ }^{2}$

For calculation of yearly incidence rates, the population denominator data were obtained from the 1981 and 1991 national census data with interpolation. The incidence was standardised by the direct method using the world population as the standard. The $95 \%$ confidence intervals were calculated assuming a Poisson distribution. The significance of seasonal variation was analysed by an ordinary $\chi^{2}$ test.

Results: The ascertainment probability for the whole study period was $90.05 \%$, ranging from $74 \cdot 04 \%$ to $98 \cdot 74 \%$. Between 1982 and 1992 , the mean, annual, age adjusted incidence rates of IDDM (per 100000) were $7 \cdot 3$ for boys, $8 \cdot 1$

Incidence rates (95\% confidence interval(CI)) (per 100000) of insulin dependent diabetes mellitus in Belgrade children 0-14 years in relation to sex, average for 1982-92

\begin{tabular}{|c|c|c|c|c|c|}
\hline & \multicolumn{3}{|c|}{ Age group (y) } & \multirow{2}{*}{$\begin{array}{l}\text { Crude } \\
\text { rate } \\
0-14\end{array}$} & \multirow{2}{*}{$\begin{array}{l}\text { Age adjusted } \\
\text { rate } \\
0-14\end{array}$} \\
\hline & $0-4$ & $5-9$ & $10-14$ & & \\
\hline $\begin{array}{l}\text { Boys } \\
\text { Cases (no) } \\
\text { Population } \\
\text { Incidence rate } \\
(95 \% \text { CI) }\end{array}$ & $\begin{array}{l}24 \\
47 \cdot 574 \\
4 \cdot 6 \\
(2 \cdot 9,6 \cdot 8)\end{array}$ & $\begin{array}{l}43 \\
51 \cdot 594 \\
7 \cdot 6 \\
(5 \cdot 5,10 \cdot 2)\end{array}$ & $\begin{array}{l}59 \\
50 \cdot 870 \\
10 \cdot 5 \\
(8 \cdot 1,13 \cdot 7)\end{array}$ & $\begin{array}{c}126 \\
150 \cdot 038 \\
7 \cdot 6 \\
(6 \cdot 4,9 \cdot 1)\end{array}$ & $\begin{array}{l}7 \cdot 3 \\
(6 \cdot 1,8 \cdot 8)\end{array}$ \\
\hline $\begin{array}{l}\text { Girls } \\
\text { Cases (no) } \\
\text { Population } \\
\text { Incidence rate } \\
(95 \% \mathrm{CI})\end{array}$ & $\begin{array}{l}16 \\
44 \cdot 610 \\
3 \cdot 3 \\
1 \cdot 9,5 \cdot 3\end{array}$ & $\begin{array}{l}55 \\
48 \cdot 477 \\
10 \cdot 3 \\
7 \cdot 8,13 \cdot 5\end{array}$ & $\begin{array}{l}62 \\
47 \cdot 500 \\
11 \cdot 9 \\
9 \cdot 2,15 \cdot 4\end{array}$ & $\begin{array}{l}133 \\
140 \cdot 587 \\
8 \cdot 6 \\
7 \cdot 2,10 \cdot 2\end{array}$ & $\begin{array}{l}8 \cdot 1 \\
(6 \cdot 8,9 \cdot 7)\end{array}$ \\
\hline $\begin{array}{l}\text { Total } \\
\text { Cases (no) } \\
\text { Population } \\
\text { Incidence rate } \\
(95 \% \mathrm{CI})\end{array}$ & $\begin{array}{l}40 \\
92 \cdot 184 \\
3 \cdot 9 \\
2 \cdot 8,5 \cdot 3\end{array}$ & $\begin{array}{l}98 \\
100 \cdot 071 \\
8 \cdot 9 \\
7 \cdot 3,10 \cdot 9\end{array}$ & $\begin{array}{l}121 \\
98 \cdot 370 \\
11 \cdot 2 \\
9 \cdot 3,13 \cdot 4\end{array}$ & $\begin{array}{l}259 \\
290 \cdot 625 \\
8 \cdot 1 \\
7 \cdot 1,9 \cdot 2\end{array}$ & $\begin{array}{l}7 \cdot 7 \\
6 \cdot 8,8 \cdot 7\end{array}$ \\
\hline
\end{tabular}

for girls, and $7 \cdot 7$ for both sexes. The highest incidence was in the age group $10-14$ years. The overall male:female ratio was 0.90 (table).

There was a year to year fluctuation in both crude incidence and estimated incidence (crude rate/completeness of ascertainment), with two peaks, one in 1985 and the other surrounding the year 1991 .

The largest numbers of new cases were identified in the months of January and September, and the smallest numbers in April, May, and June. The seasonal pattern in the total material was significantly different from a uniform distribution of new cases throughout the year $(p<0.01)$. The mean number of new cases in the winter months, December, January and February, was significantly different from the yearly mean $(p<0.05)$.

Discussion: The IDDM incidence rate of 7.7 per 100000 in Belgrade compares with rates in European countries with low-medium incidence. This rate is comparable to those in France, Hungary, Austria, and northern Italy; is higher than that in Israel; and is lower than rates in Nordic countries, in Denmark, and the United Kingdom. ${ }^{3}$ In Belgrade, however, the IDDM incidence is higher than that during the years 1989 and 1990 in Bucharest, ${ }^{3}$ which is on a latitude close to that of Belgrade. It is also higher than the rates in Slovenia and Poland, ${ }^{3}$ which are further north. There are other examples which are inconsistent with a north to south gradient. ${ }^{3}$ Taking into account year to year fluctuation and epidemic type variation in IDDM incidence, however, a north to south gradient can not be discussed on the basis of one or two year incidence rates, especially when small variations in latitude and rates of incidence are concerned. The rates in Sardinia and Iceland ${ }^{3}$ could be regarded as exceptions.

Our data confirm earlier findings that there is often a slight female preponderance in low incidence populations.

A trend of increasing incidence for childhood 